Why Do Employees Keep Choosing the High-Premium Health Care Plan? An Investigation of the Financial Consequences and Logic of Employee Health Care Plan Selections

\author{
Michael C. Sturman, \\ John W, Boudreau, \\ Richard J. Corcoran
}

In 1991, Dannon employees had the choice to stay with their current health care plan or switch to a new plan which offered a lower premium and less hospital cost coverage that better fit the needs of most employees. Both plans were the same in all other respects. Only $25 \%$ of employees chose the new lower-premium plan over the old plan. This article reports a collaborative effort between The Dannon Company and Cornell University's Center for Advanced HR Studies to identify the patterns of employee choices, and the effects of those choices on the actual costs that employees incurred. The actual decisions of 287 Dannon employees were examined, and the out-of-pocket costs that they actually incurred in the two years after the plan was introduced were calculated. (C) 1996 by John Wiley \& Sons, Inc.

Introduction

At The Dannon Company, the human resource (HR) department was enacting a strategic change: shifting from an entitlement to a partnership philosophy. The new strategy was intended to reflect a cooperative environment between management and labor with risks and benefits being shared. This strategic shift was to include many changes such as a new pay-for-performance system, increased reliance on bonus over base pay, enhanced gain-sharing, and a revised performance appraisal system. Yet Dannon managers did not want to "shock" employees by making all of these changes simultaneously. Dannon began this change by offering its employees a new health care plan which required greater cost-sharing on part of the employees, but offered a lower premium. For most employees the premium savings were expected to more than offset any additional costs incurred by greater cost-sharing. Dannon managers expected that the majority of employees would welcome the savings that would result from such an option and enroll in the new plan. Dannon also felt, however, that a minority of employees would resist the change, so employees were allowed to pay a higher premium for the more extensive coverage. 
Prior to 1991, all employees had automatically been enrolled in the old plan, a typical fee-forservice $^{1}$ (FFS) plan that covered $100 \%$ of all hospital- related medical claims. In 1991, employees could choose to stay with the old plan or choose a new plan which offered a lower premium and covered $80 \%$ of hospital costs. The two plans were provided by the same insurer, communicated and marketed similarly, had similar claims procedures, offered the same amount of choice among health-care providers, etc. The company had no preferred-provider networks. The only differences between the two plans were their premiums, deductibles, and reimbursement rates for hospital expenses. Both plans also had a comparable out-of-pocket cap which was a maximum that employees would have to pay for uncovered health care costs before the insurance paid $100 \%$ of all costs.

Because Dannon employees seldom incurred extremely high hospital costs, employees would typically save money by taking the new lower-premium plan. For most employees, the new plan offered the certainty of a lower premium which was expected to more than offset any additional hospitalrelated costs. Dannon managers expected employees to respond to the lower premium, projecting that $75 \%$ would switch to the new plan. In fact, less than $25 \%$ switched.

Dannon managers thus faced a dilemma: The enrollment patterns were troublingly different from what had been predicted, but the reason was not obvious. It was unclear whether Dannon should provide greater inducements to encourage employees to enroll in the new plan (such as raising the premium on the old plan or forcing everyone to adopt the new one), provide better communication about the likely effects of the two plans to help employees make more informed decisions, or accept the "majority rule" by going back to the old strategy of offering only the old plan. In essence, Dannon managers wanted to know if the enrollment patterns reflected rational benefits decision-making behavior or if it signaled resistance to the new partnership philosophy. A deeper investigation was needed, so a cooperative effort between The Dannon Company and Cornell's Center for Advanced HR Studies (CAHRS) was initiated. Though it would have been difficult or impossible to reliably reconstruct the reasons for employees' decisions, it was possible to determine the results of those decisions in the form of costs to the employees. This research required collaboration, because the necessary data could only be acquired with the approval and assistance of The Dannon Company, while the theoretical knowledge resided in the CAHRS research team. Drawing on research and theory, a study was designed to provide some answers to Dannon's policy questions, as well as to fill a gap in the research on benefits decision making.

The study of health care benefit choice in flexible benefit plans is significant to managers, policy makers, and health and labor economists (Barringer \& Mitchell, 1994; Gerhrt \& Milkovich, 1992; Short \& 
Taylor, 1989). Many studies have espoused the importance of specifically looking at price-sensitivity (Barringer \& Mitchell, 1994; Feldman, Finch, Dowd \& Cassou, 1989; Short \& Taylor, 1989).3

At first glance, the enrollment pattern experienced at Dannon seemed contrary not only to the managers' predictions, but too much prior research as well. Prior studies have shown that health care benefit choices are influenced by factors affecting employees' costs, such as the premium, deductible, and copayment. ${ }^{2}$ Writers have also promoted flexible benefit plans because they purportedly provide employees an opportunity "to choose their own reward package so that it is sure to fit their needs and desires" \{Lawler \& Jenkins, 1992, p. 1046).

Upon closer examination, however, it is clear that the effect of differences in premiums or other cost elements on choices (sometimes called "price elasticity") has varied greatly across studies. Employees do not always choose the plan with the lowest premium, copayment, or deductible. Perhaps this is because some employees emphasize factors other than cost in making their decisions, as discussed below; or perhaps the benefits choice decision is simply too difficult, so people make choices out of ignorance (Mamorsky, 1990; McCaffery, 1992; Rosenbloom \& Hallman, 1981). For example, while past research shows that high-premium plans are chosen less frequently, this pattern is different depending on the employees' age, gender, family situation, and the types of plan options offered. Such differences may reflect rational factors such as the probability of children's medical expenses, the probability of a serious illness, or intangible plan elements such as the choice of physicians; but no prior study has actually measured the reasons employees choose certain plans; and few studies have measured the costs that employees actually incur after making certain choices.

Premiums, deductibles, copayments, and out-of-pocket caps are all just characteristics of health care plans; they are only signals of cost-related elements. A more direct examination of costs should provide both a more accurate estimate of price-sensitivity and a more effective tool for estimating enrollment patterns.

A clue to the reasons for employees' choices might lie in the results of those choices. While many results are not observable, such as peace of mind, comfort with a traditional plan, or flexibility in choosing doctors, some results are observable. It is possible to tell if the choices employees make eventually lower their out-of-pocket medical costs. If they do, that provides some evidence that employees either predicted their medical costs well (and chose the plan that would lower them), or that they changed their medical behaviors to fit the choices they made.

We investigated the relationship between employees' choice of health care plans and the resulting total out-of-pocket costs incurred by each employee (including insurance premiums and 
payments for uncovered expenses) for that year. As in other research ${ }^{3}$, the effects of demographic variables (age, gender, number of children, etc.) that others have shown to associate with plan choices were examined. However, this study went beyond prior work by determining if the choices led to the lowest cost for employees. Like past research, theories about employee choices having received some prior support we reused, but we went beyond past work by using theory to predict a specific pattern of cost results and testing whether that pattern emerged in our data.

Though this study looks at one choice situation, this scenario is not atypical. Within flexible benefit plans, health care choices are the most common benefit offered (EBRI, 1993). Although some flexible benefit plans include myriad benefit types (e.g., dental, disability, 401(k)), a choice of only health care plans is common (Hewitt, 1994). For health care benefits, there is also no typical choice situation. The range of options includes the choice of two to four fee-for-service (FFSs) plans, and sometimes offer Health Maintenance Organizations (HMOs) and Preferred Provider Organizations (PPOs) (EBRI, 1991). Although HMOs and PPOs are growing as a percentage of the types of health insurance plans offered, FFS plans are still the most prevalent kind of medical insurance (United States (U.S.) Bureau of Labor Statistics, 1990). The choice provided here is arguably simple but not unusual. The nature of this decision situation precluded the opportunity to study other potential effects such as differing selection of doctors, plan administration, or FFS versus $\mathrm{HMO}$. Although these factors may be significant in other benefit decision situations, and certainly merit study, it is valuable to obtain a better understanding of the effects of cost and risk-aversion in a controlled setting.

Theory and Research on Health Care Choice

Two theories suggest possible choice patterns for employee medical benefits: Expected Utility Maximization and Prospect Theory.

\section{Expected Utility Maximization Theory}

Expected Utility Maximization (EUM) theory (Friedman \& Savage, 1948) suggests that employees will select the health care plan that they believe maximizes their "expected utility." The theory proposes that individuals compute expected utility by multiplying the probability of each relevant outcome by the value of that outcome to the individual and then adding the products across all the outcomes. Health-care choice outcomes can be financial or nonfinancial. They might include cost elements such as premiums, but they might also include subjective elements such as familiarity with a past plan, access to certain doctors, confidence in a particular insurance provider, etc. 
Even simple health care choices involve more than just price. Employees must often balance minimizing costs against minimizing risk. Minimizing costs may involve trying to pay the smallest amount of money or choosing the plan that protects best against large losses. One example of risk-minimizing is choosing to pay a higher premium to insure against a large, even improbable, loss. Minimizing risk and minimizing costs, however, are not necessarily mutually exclusive. For example, if an employee expects to have expensive surgery in the next year, the low-cost and low-risk choice may be accomplished by choosing a more comprehensive plan. The more certain an employee can be about future medical costs, the more costs, rather than risk, will influence the decision. EUM theory suggests that people will generally favor those options that have the highest value on the most important dimensions, with the most certainty. The utility, or value, of a plan depends not only on the plan's characteristics but also on the certainty with which outcomes will occur.

People are predicted generally to prefer less uncertainty and lower costs. Obviously each person's utility function (what they consider to be important, the uncertainty they perceive, tolerances for risk, and the value of different option characteristics) differs; and it is not possible to observe individual utility functions directly. Past research based on this theory has observed individual choices and then deduced possible utility functions based on the characteristics of the individuals and the health care choices.

For example, older workers face higher potential medical expenses (Feldman et al., 1989; Mitchell, 1988). EUM theory suggests that older workers choose more comprehensive coverage to compensate for this risk. Despite significant effects shown for age predicting health insurance choice (Barringer \& Mitchell, 1994; Feldman et al., 1989; Short \& Taylor, 1989), however, studies have not actually measured whether older workers actually make such calculations.

Past research using EUM theory to explain employee reactions to the cost elements of health care choices has shown that plans with higher cost elements (such as higher premiums, copayments, or deductibles) are generally chosen less frequently, suggesting that employees are sensitive to costs (Barringer \& Mitchell, 1994; Marquis \& Holmer 1986; Welch 1986). Some studies have also shown that plans with higher cost elements are chosen by some people, such as those with higher incomes, older workers, and females (Barringer \& Mitchell, 1994; Holmer, 1984; Short \& Taylor, 1989). In the past, researchers have used EUM theory to explain the choice patterns by assuming that observed choices reflect people's informed attempts to maximize their expected utility. EUM theory thus provides a framework for inferring the choice processes from the pattern of actual choices. 
For this study, we were concerned only with the effects of the cost-related elements of health care choices because at Dannon, the two choices differed only in these elements. Drawing on past research, it would be expected that plan choice is affected by the cost elements of the options; three limitations of this past work make this conclusion somewhat ambiguous:

1. the options available in past studies have often varied on many dimensions, not just on costs; and different studies have focused on situations with very different sets of options making it very difficult to isolate the effects of plan costs and to compare results across studies;

2. past research has observed a wide range of sensitivities to cost elements which, given the wide variety of choice situations, makes estimating price sensitivity in other situations very difficult; and

3. costs have been measured in different ways, with some studies attempting to estimate what employees might believe their future costs would be; others representing cost only as differences in plan premiums; and some representing costs as a combination of plan cost elements such as premium, deductible and copayment levels.

In sum, while past research using EUM theory provides a valuable framework suggesting that there are predictable choice patterns, the diversity of situations studied, the failure to isolate costs as a choice factor, and the failure to measure the results of employee choices make it extremely difficult to draw firm conclusions. We felt that a contribution could be made by a study in which health care options differed only in their cost elements and where the cost-related results of the choice pattern could be analyzed. Such a study would better depict the sensitivity of employees' choices to the cost elements of the plans and reveal whether those choices actually resulted in lowering employees' medical expenses. If EUM theory was correct, we would expect to see employees choosing plans that minimized their eventual out-of-pocket costs.

One element missing from the previous discussion is the element of uncertainty. Employees may be unable to predict their future medical expenses. Only two studies have examined the predictability of future medical expenses. Van Vliet (1992) found that only about $20 \%$ of the variability in future medical expenses could be predicted using demographics information and past medical expenses. On the other hand, Ellis (1989) found that up to $74 \%$ of the variance in future out-of-pocket expenses could be predicted by prior out-of-pocket expenses. Prior research provided mixed information about the likely uncertainty facing employees making such choices. If future medical expenses were very 
predictable, then uncertainty and risk might play only a small role in decisions. If future medical expenses were very unpredictable, then uncertainty might be a very salient factor.

Looking at employees' actual costs after they made their decisions would be instructive. If employee choices seemed strongly associated with later costs, then future costs were either predictable enough for employees to choose the plan that best reduced them, or employees could adjust their behaviors (e.g., choices about routine office visits) to fit the plan they chose. In either case, costminimizing behavior would suggest that employees can anticipate their future costs. On the other hand, if no systematic relationship was found between choices and costs, then future medical costs are generally unpredictable and giving employees benefit choices may not be valuable.

EUM theory suggests that employees deal with this uncertainty by calculating their best guess about the probability of future events and choosing the option that produces the highest probabilityweighted value. More certain events get more weight than uncertain events. EUM theory, however, also predicts that uncertainty itself is an element of choice and that people have different preferences for uncertainty, called "risk preference" or "risk aversion." EUM theory predicts that people generally prefer options with less risk. For example, most people will not pay $\$ 10$ for the right to play a game with a $50-$ 50 chance of winning either zero or $\$ 20$. They prefer the certainty of keeping their $\$ 10$ to the $50 \%$ chance of winning $\$ 20$, even though the "expected value", the probability-weighted outcome, is the same under both choices.

For health care insurance choices, EUM theory suggests that employees would have some preference for options that reduce uncertainty. Prior studies have noted that risk-aversion affects health care plan choice (Barringer \& Mitchell, 1994; Friedman, 1974; Short \& Taylor, 1989). Researchers have consistently found that employees have a strong preference for minimizing risk, often demonstrated through a high willingness to pay larger premiums for protection against catastrophic expenses. Even though plans frequently limit maximum out-of-pocket expenses, the risk-aversion tendency is still prevalent.

Prior research thus suggests that employees might pay more in premiums for a plan that better protects them from costly medical expenses, even if the chance of those medical expenses is small. While EUM could provide this general prediction, it does not say how much people will pay for such protection or how likely the high-cost medical events must be to justify paying more for the protection. Yet these patterns may cause enrollment patterns to vary significantly. In the Dannon case, it was possible that people chose the high-premium plan because the difference in premiums was seen as small compared to the value of protection against possible high hospitalization costs. EUM theory and 
past research predicted this possibility, but more research was needed to see if this actually occurred. At Dannon, about $75 \%$ of employees chose the high-premium plan, but looking at choice patterns alone would not reveal why. We needed to look at the actual medical costs incurred by employees to determine the likelihood of the catastrophic medical expenses, so that we could tell if the choices seemed to emphasize the unlikely large medical expenses or the certain difference in premiums.

Prospect Theory

While EUM theory suggests that uncertainty plays a role in decisions. Prospect Theory describes more precisely the nature of the effect of uncertainty Although the majority of health care insurance choice research has used EUM theory to guide its hypotheses. Marquis and Holmer (1986) and Ellis (1989) provided evidence suggesting that prospect theory (Kahneman \& Tversky, 1979) helps explain employee behavior better than EUM.

Prospect Theory (Kahneman \& Tversky, 1979) predicts that people facing risky choices (or "prospects") will react to losses more strongly than to gains (e.g., losing $\$ 100$ is more significant than winning $\$ 100)$, that differences between very large gains and losses are not weighed as heavily as differences between smaller gains and losses (e.g., people will not pay one thousand times more for the chance to win $\$ 10,000$ than they will pay for the chance to win $\$ 10)$, and that gains and losses are judged relative to a reference point (e.g., paying $\$ 50$ for something feels better when the price represents a discount from an earlier price, than when it represents a mark-up).

For the health care selection decision. Prospect Theory postulates the following:

1. value is a function of the gain or loss in non-medical consumption with respect to some reference and not to overall wealth;

2. the value function is asymmetric (i.e., more disutility for losses than utility for gains);

3. the value function is usually concave for gains and convex for losses; and

4. riskless elements of a choice are valued separately from the uncertain elements of a choice (Ellis, 1989; Marquis \& Holmer, 1986).

Prospect Theory suggests that employees would evaluate the outcomes of their choices relative to a reference point; however, aside from stating that this reference point is not overall wealth, it does not specify this reference point. We decided to use the "making the low-cost choice" as our reference point. That is, we calculated the difference in costs between making the low-cost choice and the highcost choice. The larger this difference, the more likely that employees would choose the low-cost 
option. Prospect Theory also predicts that the reaction to this difference would be proportionately stronger if the differences occurred near the reference point than if it occurred far away from the reference point. For example, we expected to see a greater increase in people choosing the low-cost plan when we compared those who stood to save nothing to those who could save $\$ 200$, than when we compared those who stood to save $\$ 700$ to those who stood to save $\$ 900$. This could have important implications for managers, because it would mean that adjusting premiums on competing plans would depend on the reference point that people used. Not everyone would react similarly to a $\$ 200$ increase in premiums.

\section{Out-Of-Pocket-Costs(OPC)}

While theory has provided a potent framework for studying employee benefit choices, the reactions of employees to the cost elements of benefits have not been thoroughly examined because (a) past research faced situations in which benefit options varied on factors other than costs, or because (b) past research did not measure the results of employee decisions. In the present study, we had an opportunity to address these problems. First, the two benefit choices at Dannon differed only in elements that affected their costs, so other factors were held constant for these employees. This forced employees to focus on costs, which provided us with the opportunity to isolate these effects.

Second, we were able to measure the actual costs that employees incurred after making their choices. Past studies of benefit costs have not measured the actual costs incurred by employees. Most studies simply observed different plan characteristics such as the premium, deductible, and co-payment, or used statistical techniques to approximate future medical costs from past information. ${ }^{4}$ Because we could calculate actual out-of-pocket costs directly, we could observe the actual financial ramifications of employee choices. If employees choose plans with coverage they do not use or choose low-premium plans that do not provide enough coverage, out-of-pocket costs will show this clearly.

The ideal study would measure employees' anticipated medical expenses and determine whether those expectations predict benefit choices and whether the anticipated expenses accurately predicted the employees' future medical costs. In our case, as with every study to date, we could not go back and reconstruct the anticipations of employees. We could only calculate out-of-pocket costs after choices were made and expenses incurred. For example, if an employee's choice does emerge as the low-cost option, we cannot tell whether the employee selected the plan because s/he correctly anticipated future costs, or whether s/he made his/her choice and then adjusted his/her behaviors to fit the coverage of that plan. If the realized costs significantly associate with choices, we can surmise that 
one of these two processes is at work. At the very least, we can conclude that health care costs are not so unpredictable that informed choices cannot be made.

Estimating OPC requires three pieces of information: (1) plan premium; (2) individual medical charges; and (3) the reimbursement characteristics of the plan. For example, suppose an employee pays a premium of $\$ 100$ for a medical insurance plan that will pay 80 percent of the first $\$ 1000$ of medical expenses and $100 \%$ thereafter. Such a plan creates an OPC function that has a minimum of $\$ 100$, rises by 20 percent for each dollar of medical expenses up to $\$ 1000$, and reaches a maximum of $\$ 300$ (i.e., the $\$ 100$ premium plus 20 percent times $\$ 1000$ ). Similar functions can be constructed for any medical plan if the data are available.

Using OPC, Financial Regret, can be calculated, defined as the financial consequence of making a not-cost-optimal choice. With an individual's actual medical cost experience, OPC can be calculated for each available choice. If the employee chose the option that minimizes his/her OPC, then Financial Regret equals zero. If the employee chose a different option. Financial Regret equals the difference between the OPC of his/her chosen plan and the cost-optimizing plan.

The Value of Giving Employees a Choice

Flexible benefits are predicated on the idea that employees can make choices that best satisfy their needs (Lawler \& Jenkins, 1992). One study did find that benefits satisfaction rose after employees were given a choice of benefits (Barber, Dunham, \& Formisano, 1992), but it is not clear why this occurred. Do employees really choose plans that are better for them, or does choice merely give the illusion of control? In the Dannon case, the plans varied only in the way costs were treated, so all but the cost-related needs were held constant. Thus, we could examine the value of giving employees a choice by looking at the costs they incurred.

Again, the value of choice depends on the level of uncertainty. If benefit costs can be predicted (or behaviors changed to reflect past choices), then giving a choice may be very valuable. Past studies (van Vliet, 1992; Ellis, 1989), however, have shown mixed results regarding the predictability of health care costs. Though van Vliet (1992) estimated that only $20 \%$ of future benefit costs could be predicted, there were many variables that he could not measure, but that would be known to individuals (e.g., an impending birth, an upcoming expensive elective medical procedure, etc.). Though Ellis showed that past medical costs could be used to predict fairly accurately the future category of medical costs, he did not explore whether the decisions made when employees had a choice were better than simply requiring employees to enroll in one plan or another. We set out to examine specifically whether the 
costs incurred by employees were lower when said employees were given a choice than if they were not.

The answer has important implications. If medical calamities are rare, but extremely unpredictable, then the uncertainty may prevent employees from seeing the benefit of a low-cost, lowprotection option. Employees' out-of-pocket costs may best be minimized simply by requiring employees to enroll in a plan that meets cost objectives while minimizing the out-of-pocket costs of most employees in most years. Though costs are not the only measure of value, in the Dannon case and in many others, the available options differed primarily in their costs. We could, therefore, test whether employees were better at minimizing their costs when given a choice by investigating whether the total costs paid by employees were less under the choice situation than they would have been if employees had been forced to choose one plan or the other. No prior study has made such a calculation.

\section{Method}

Sample

At the time of this study. The Dannon Company had two manufacturing plants in the United States in addition to its headquarters location. At this time, Dannon employed roughly 650 people. Beginning in 1991, one plant with 340 employees offered the choice between two health care plans. Data on employee choices, medical billings, and demographic characteristics were collected for 1991 and 1992 from the plant that offered the choice. Data were collected on individuals employed for both of these years from the company and from the medical insurance provider. The cooperation between Dannon and the insurance provider demonstrates the value of multi-organization partnerships. Although Dannon outsources certain aspects of the benefit administration function to specialists, information easily flows to and from these sources. This information can be used to aid managerial decision making, to support policy decisions, or to conduct research. While out-sourcing does allow Dannon to take advantage of specialist efficiency, Dannon does not lose the ability to retain critical information that can add value in other human resource activities.

A total of 287 cases were obtained in both 1991 and 1992. Data included employee age, sex, marital status, number of children, and medical billings. The average employee age was 34 years; $63 \%$ were male; 78\% were married; and each employee had roughly 2 children (mean $=1.7$; ranging from 0 to 7$)$. Medical expenses averaged $\$ 4,052$ with individual expenses ranging from $\$ 0$ to $\$ 191,786$. 
Nature of the Choice Situation

For research, the data offered many advantages. Each individual faced the same choice between two health care plans. The health care plans were both fee-for-service plans, provided the same access to doctors, were provided through the same organization, were similarly marketed, and had the same claims procedure. This allowed us to isolate the effects of cost on choice.

This control did not occur because of experimental manipulations. When Dannon provided employees with choices, Dannon managers wanted employees to continue to receive the same flexibility and quality of care that they had previously received. A fundamental purpose of providing choice was to give employees an opportunity to lower their costs. Dannon, therefore, offered two plans that differed only in their premiums, deductibles, and rates of reimbursement. Table 1 provides the specific characteristics of the plans.

Measures

We measured the out-of-pocket costs (OPC) that employees actually incurred in the year following their choice, as well as the OPC they would have incurred if they had chosen the other plan. OPC was calculated for each employee based on his/her total medical expenses (i.e., hospital and nonhospital) and plan characteristics (see Table I). For example, if a single employee had $\$ 1000$ in nonhospital-related medical expenses and $\$ 5000$ in hospital-related medical expenses, the OPC for Plan A and Plan B would be calculated as follows: Under Plan A, the premium is $\$ 231.36$. Of the $\$ 1000$ in nonhospital-related medical expenses, the employee must pay a deductible of $\$ 100$. Of the remaining $\$ 900$, the employee pays a $20 \%$ co-payment: an additional $\$ 180$. Hospital costs are fully covered. The total OPC for this employee under Plan A is $\$ 511.36$. Under Plan B, the premium is $\$ 79.56$. Hospital and nonhospital costs are combined ( $\$ 6000)$, and the employee pays a deductible of $\$ 200$, and then $20 \%$ of the remaining $\$ 5800$ medical expenses $(\$ 1160)$. Thus, the OPC under Plan B is $\$ 1439.56$. In this case, the low-premium plan B is the more costly option because of the high hospital costs.

We defined Financial Regret as the consequence of choosing the plan that eventually costs more. Continuing the above example, if the employee chose Plan A, then Financial Regret equaled \$0 because Plan A turned out to be the lowest-cost choice. If the employee chose Plan $B$, then Financial Regret equaled $\$ 928.20$, or the difference between the OPC of Plan B and the OPC of Plan A. Potential Financial Regret was also computed for each individual. This was the amount of regret the person would have felt if s/he had chosen the higher-cost option. It is a measure of how high the "stakes" were for employee decisions. In this example. Potential Financial Regret equals \$928.20. 


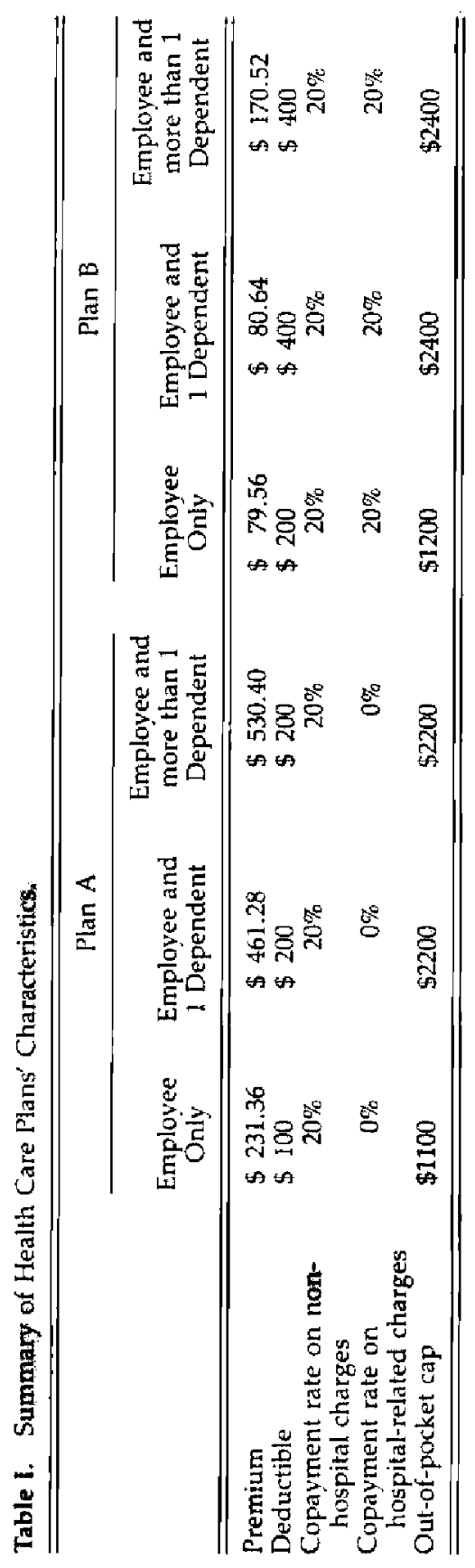

Results

Table II shows how often employee choices turned out to be the lowest-cost, the cost consequences of actual employee decisions for each year, and what would have happened had all employees been forced into either plan. The rows of Table II correspond to the different choices or 
benefit policies and the two different years. The first seven rows reflect the results based on the actual choices. The remaining rows show the consequences of not providing employees with choice.

Results largely support the notion that providing employees with choice allowed them to select more lower-cost plans. Although the rate of cost-optimality of actual decisions was less than half (48\%), over the two years employee decisions translated into savings for the employee population. Combining the two years, the OPCs associated with actual decisions were less than the OPC associated with forcing all employees to select Plan $A[t=3.37 ; p<.001)$ or Plan B $\{t=3.96 ; p<.0001)$. Analyses of the results within each year are the same, except that the OPCs associated with actual decisions were nearly the same as the OPC of all employees being covered by Plan A in $1991\{t=.04 ; n . s$.$) . The OPCs of actual$ decisions were significantly lower than the OPCs of all employees having Plan $A$ in $1992\{t=7.19 ; p<$ $.0001)$, Plan B in $1991(t=2.93 ; p<.01)$, and Plan B in 1992, $(t=2.67 ; p<.01)$. These Financial Regret levels translated into substantial consequences for employees. By providing employees with a choice instead of continuing to give employees only the comprehensive plan (i.e., Plan A), the 287 employees saved a total of $\$ 14,236$ per year. Providing a choice, instead of requiring employees to select the new plan \{i.e., Plan B), allowed the employees to save $\$ 36,699$ per year.

The data in this study did not allow the calculation of risk-aversion as performed in other studies (e.g., Friedman, 1974; Marquis \& Holmer, 1986); however, analysis of choice patterns does suggest that employees care about risk. As shown in Table II, employees were more likely to choose the comprehensive (less risky) plan, regardless of which plan was lowest cost. Still, choosing the comprehensive plan was more likely when Plan A also turned out to be low-cost choice than when Plan B turned out to be low-cost $\{t=4.53, p<.0001)$. Table II illustrates this because the probability of costoptimality was much higher for those choosing Plan B than for those choosing Plan A (Column 5, Rows 1 vs. 2 and Rows 4 vs. 5). Thus, it seems that the selection of Plan B is highly related to later costs, but the selection of Plan A is less so.

Does Higher "Stakes" Associate with Choosing Low-Cost Options?

We used logistic regression to determine how strongly Potential Financial Regret (the potential cost of making a non-cost optimal decision) affected whether employees made decisions that turned out to be low cost. This statistical approach removed the possible effects of personal characteristics, such as age, sex, etc. The purpose of removing the influence of demographic variables is to avoid confounding their effects with the effects of Potential Financial Regret. For example, those with children may prefer a low-premium plan because they have less money to spend on medical insurance. We want to remove 
the effects of number of children so that our analysis of Potential Financial Regret measures only the effect of this one variable and not of any other phenomenon.

Table III reports results for the model predicting the realized cost-optimality of employee choices using employees' sex, marital status, number of children, age, year in which decision was made, and the logarithm of Potential Financial Regret. (Note that the natural logarithm, or "log," was used to make the distribution of Potential Financial Regret more compatible with this statistical technique.)

Several variables were significantly related to the probability that employees' decisions produce the minimum OPC. Specifically, being male, having more children, making the decision in 1992 versus 1991, and higher Potential Financial Regret were all significantly and positively related to that probability. Regarding the gender effect, additional analyses (not shown here but available from the first author) showed that women were more likely to select the high-premium, high-coverage plan than were men. Perhaps women are willing to pay more for protection against unlikely future medical calamities, or perhaps they face greater uncertainty about their future medical expenses. Having more children may be associated with making the low-cost decision for a number of reasons. Those with children may have greater financial obligations and make choices more carefully. They may have more ways to adjust their medical expenses to fit the plan they choose (e.g., more decisions about whether to see a doctor for relatively minor health problems), or they may have more predictable medical expenses. Additional analyses did not suggest that those with more children were more or less likely to choose the highpremium plan. That employees' decisions emerged as low-cost more in 1992 than in 1991 may reflect a learning effect, as employees either learn to choose benefits that eventually fit their needs better or they learn to adjust their behaviors to fit their choices.

For managers, these patterns may suggest that certain groups wilt benefit more from choices than will others (if we accept lower costs as a definition of the benefit of choice). Perhaps those who seem to fail to minimize costs could most be helped by additional education about their choices. Or, if those whose choices emerge as low-cost are lowering their costs by adjusting their behaviors to fit their choices, managers can focus on these groups to determine how and why such adjustments are possible. Perhaps other employees could learn from those who are most successful at lowering their out-ofpocket costs. 
Table III. Determinants of Cost-Optimality:

Logistic Regression Model (Probability

of Employee Making a Cost-Optimal

Decision as Reference Category).

\begin{tabular}{cc}
\hline \hline Variable & $\begin{array}{c}\beta \\
(t-\text { value })\end{array}$ \\
\hline \hline Sex & $-0.23^{* *}$ \\
(Male $=0 ;$ Female $=1)$ & $(2.47)$ \\
Married & 0.15 \\
(Single $=0 ;$ Married $=1)$ & $(1.06)$ \\
\#Children & $0.12^{*}$ \\
& $(1.77)$ \\
Age & 0.012 \\
Year & $(1.16)$ \\
$(1991=0 ; 1992=1)$ & $0.36^{*}$ \\
Ln Potential Regret & $(2.01)$ \\
& $0.70^{* *}$ \\
\hline \hline Pseudo $R^{2}$ & $(6.30)$ \\
Log Likelihood & 0.10 \\
$N=574$ & -365.88 \\
\hline \hline " $p<.05 ; * *<.01$. & \\
\hline
\end{tabular}

The significant relationship between Potential Financial Regret and the probability that the decision emerged as lower-cost has important implications. These results mean that the more an employee's eventual medical claims favored one option, the more likely that the employee had chosen the lower-cost option. The extent of the relationship, however, was not the same at all levels of cost consequences. This is seen most easily in Figure 1, which graphs the probability that the choice emerges as lower-cost against the actual cost difference between the two choices. Notice how the graph first rises steeply and then levels off. This means that differences close to zero are more highly related to the probability than are differences far from zero. Those facing a cost difference of $\$ 500$ were much more likely to have chosen the lower-cost plan than were those facing a cost difference of zero. Those facing a cost difference of $\$ 1500$, however, had about the same likelihood of having chosen the lower-cost option as those facing a cost difference of $\$ 2000$. Recall that this is exactly what was predicted by Prospect Theory, it supports our use of cost-minimization as the prospect reference point. It is consistent with the theory that says employees place a value on outcomes that depends on their reference point. In this case, the reference point is "making the low-cost decision," and it appears that 
employee choices are more sensitive to differences close to the reference point than to those farther away.

\section{Practical Implications}

When organizations introduce new benefit choices, the success of the strategy often depends on understanding how employees will respond. More accurate prior knowledge of enrollment patterns would allow managers to better forecast administrative costs, better educate the employee population, or even help determine if offering a choice of benefits is of any value. This study adds to our knowledge about how employees respond to choices about health care benefits, in a specific, but typical, situation where the non-cost elements were equal across the choices. We found that theory and research about human behavior and reactions to uncertainty helped us to estimate more precisely the patterns of and the reasons for choices made by Dannon employees.

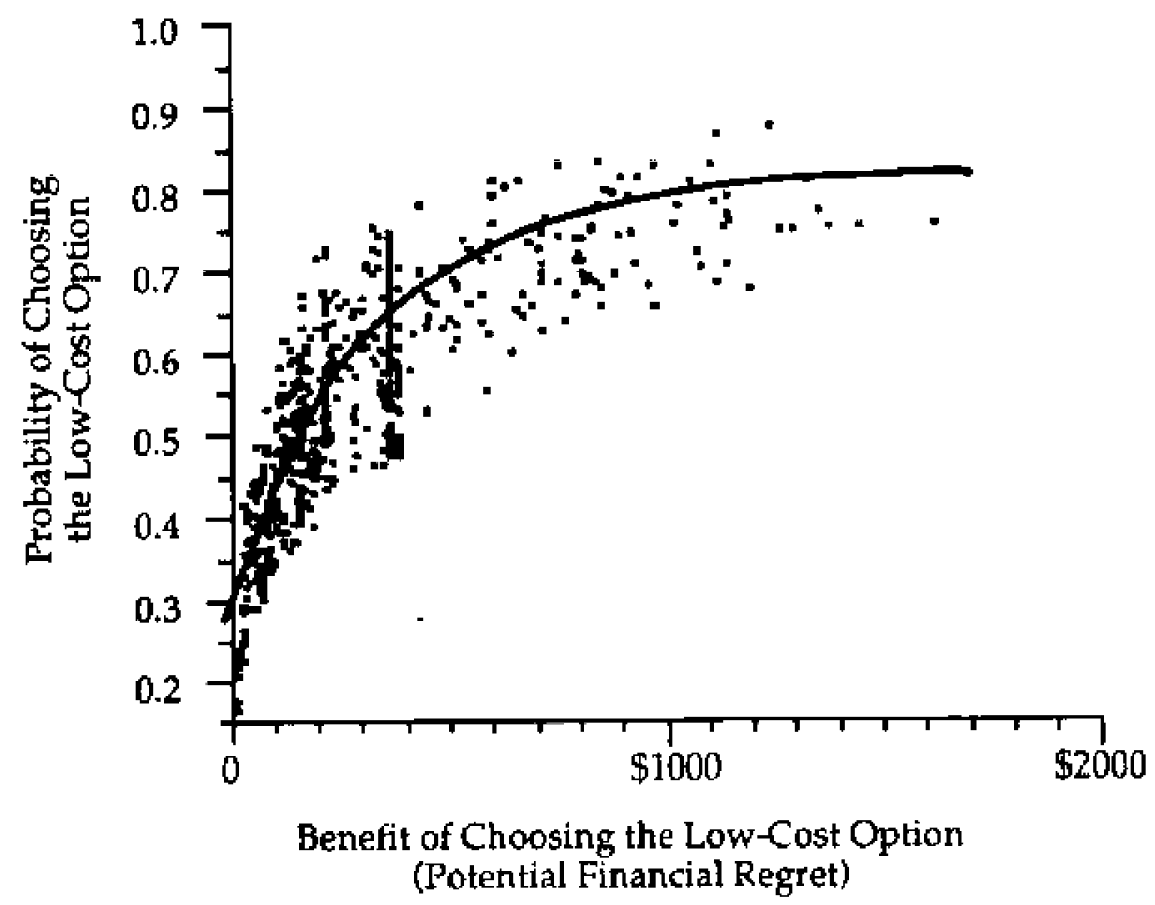

Figure 1. Probability of cost optimality by Potential Regret.

We developed a measure of decision consequences, out-of-pocket costs, which had been proposed before, but had only been measured in one prior situation (Ellis, 1989). No prior work had used the pattern of realized OPC to examine the possible reasons for employee decisions. Additionally, OPC provides a means to unify differing benefits measures. Because premium, copayment rate, and deductible often do not vary enough within any sample of plans, analysis of each of these elements in a combined model is frequently impractical (e.g., Barringer \& Mitchell, 1994; Short \& Taylor, 1989). 
Further, OPC might explain some contradictory findings. For example, Feldman et al. (1989) found that the size of the out-of-pocket maximum was positively related to the probability of choosing that plan. While this at first might seem counterintuitive, higher premium plans tend to have lower out-of-pocket caps. Thus, because the effect of premium was very significant in their study, it makes sense that the analysis might reveal the opposite relationship than expected for out-of-pocket caps. Similar findings, such as unexpected significant results for factors such as copayment and deductible, can also be explained by large premium effects. When OPC is used, however, researchers can directly examine the role of costs in the benefits decision. Future benefits managers might well incorporate OPC into their own planning and benefits evaluation processes, because it proved to reveal interesting and counterintuitive results.

Specifically, we found that although Dannon managers and many prior researchers have suggested that employees would respond favorably to a low-premium choice, only $25 \%$ of Dannon employees made that choice. Moreover, most employees' choices did not turn out to minimize their later out-of-pocket costs; those employees incurred costs averaging \$220 per year and ranging as high as $\$ 1642$ per year. Overall, the total amount of extra out-of-pocket costs paid by the 287 employees (compared to the hypothetical situation in which every employee made the low-cost choice) was $\$ 65,613$ per year. Managers in other organizations may find it useful to calculate OPC for their own employees, perhaps as a way to motivate employees to learn more about the consequences of their choices. What may be of further interest to managers is our finding that individuals with certain characteristics were more likely to have made the low-cost choice. Specifically, males and those with more children made low-cost decisions more often, and decisions in the second year of the plan were more likely to emerge as lower cost. This suggests that managers might want to examine how the benefits decision processes differ along these characteristics. Three possibilities are particularly intriguing and lead to very different managerial implications. First, certain groups may make the lowestcost choice because they are better at anticipating their future medical expenses and/or they better understand the choices and their consequences. Second, those who make the lower-cost choice may simply place more value on reducing out-of-pocket costs, compared to some other outcome such as having protection from medical calamities. Third, those whose choices emerge as lower-cost may change their medical behaviors to "fit" the plan they chose. Our data cannot distinguish among these three possibilities, but our results show that the differences are real and should be studied further. If the first possibility explains the results, then benefits education may be helpful to employees. If the second possibility is correct, then benefits planners must incorporate different tastes for risk protection into 
their estimates of benefit enrollment. Finally, if the third possibility explains the results, then benefits planners must more carefully consider how the choices they offer may motivate changes in employee behaviors, and whether such changes are beneficial to employees and to the organization.

We found that employees whose medical cost pattern gave them the most to gain or lose from their choice were more likely to choose the lower-cost option. The higher the "stakes," the more likely the lower-cost option was chosen. Consistent with Prospect Theory, we also found that cost differences closer to the reference point (i.e., making the lower-cost decision) were more strongly associated with differences in the probability of choosing the low-cost plan than similar cost differences further from the reference point. For example, employees who would incur $\$ 500$ of expenses by choosing the non-costoptimal plan were much more likely to choose the lower-cost plan than were employees who would pay only $\$ 50$ for making the non-cost-optimal choice. The probability rose much less when comparing those with a cost difference of $\$ 550$ to those with a cost difference of $\$ 1000$. Benefits managers contemplating changes in benefits cost elements should keep in mind that responses to those changes will differ in relation to the cost associated with making the non-cost-optimal decision.

Dannon managers might have motivated more employees to switch to the new plan by raising the premium on the old plan. Dannon managers chose not to do that for fear that employees would have perceived the change as a penalty on those choosing to continue with their old familiar healthinsurance plan. Dannon managers focused on introducing a lower-premium alternative to gauge the response of their employees to the choice process without risking the backlash associated with a price increase.

Though most employees individually did not choose the lower-cost option, the out-of-pocket costs borne by all employees as a group were lower than if they had all been assigned to either plan. This suggests that groups of employees can achieve lower overall costs with choices than without. This is the first study to demonstrate this result empirically. For managers, this finding lends some support for offering benefit choices, even when most employees will not make the low-cost choice. Some have promoted benefits choices as allowing employees to configure benefits that are "sure to fit their needs and desires" (Lawler \& Jenkins, 1992, p. 1046). Whether Dannon employees did this cannot be determined from our data, because out-of-pocket costs are only one element of employee "needs." In this situation, where non-cost plan attributes were identical, most employees did not make the choice that eventually minimized their costs. Our results must be replicated across a wider variety of situations to make any firm conclusions about the full value of offering employees choices, but hopefully these findings will motivate further work, and provide an example of how such work might proceed. 
At the very least, our results suggest that informing employees of the out-of-pocket cost implications of their choices may be useful to them. Many organizations provide tables that show the cost implications of different choices for different "typical" situations (e.g., single versus married, children versus not). It may be even more useful to show each employee the cost implications of his/her choices based his/her own individual medical cost pattern, using OPC as the measure of the cost consequences. We know of no research that has yet examined the effects of such a strategy, but our results suggest that employees may well respond quite strongly to such information. The fact that choices were more cost-optimal in the second year also suggests that learning may affect choices, which lends further support for using OPC as a communication device.

The results from Table III can also be used by Dannon managers to predict changes in benefit choices and monetary effects for the employee population resulting from a given premium increase. Specifically, projections of optimality can be made after making hypothetical changes to the dependent variables. For example, we might want to estimate what would have occurred had Plan A been introduced with a $\$ 100$ larger premium. First, the OPC for Plan A is recalculated (i.e., increased by $\$ 100$ ). Then, Potential Regret is recalculated, and the coefficients derived from the original sample are reapplied using the new values of the dependent variables. Enrollment patterns can then be estimated based on the new Potential Regret values (assuming that the planned change would not change people's use of medical benefits). Although such calculations require the use of a statistical package, they can be simple to perform and can yield valuable findings.

Continuing the above example, if Plan A was introduced with a $\$ 100$ higher premium, we would expect the following: more employees would have selected Plan B, more employees would be costoptimal; and total out-of-pocket costs would increase. Unfortunately, this prediction is all that previous research would have led us to conclude. On the other hand, the findings of this study allow policy makers to produce specific estimates of the effects of policy changes. Estimates from this analysis (available from the first author) reveal that 74 more employees would have chosen Plan B over the two years. Although this analysis assumes that medical expenses would have remained unchanged, this sort of analysis allows decision-makers to be more specific than they could from prior studies.

This method can be easily expanded to examine a wide variety of changes, such as for premium, copayment, and deductible. Certainly, Dannon managers can use these results to predict enrollment patterns for any sort of changes in their benefits plan. Because almost any organization can acquire medical expense data on its own employees, a company can use these methods to make similar projections for its own work force. In sum, aside from using OPC to investigate cost-sensitivity more 
directly, this study provides managers with a useful method for projecting the effects of health care plan changes on employee enrollment patterns.

Future Research and Study Limitations

We set out to examine whether the propositions of Expected Utility Maximization Theory and Prospect Theory would explain the pattern of employee benefits choices and resulting costs. Our results largely sup-port these two theories. Employees who had the most to gain or lose chose the lower-cost option more frequently, suggesting that their choices, or their subsequent behaviors, were designed to minimize their out-of-pocket costs. It also appears that those choosing the more protective plan were less likely to eventually minimize their OPC, suggesting some willingness to pay for the added protection, though our data cannot unequivocally support or refute this explanation. Finally, Figure 1 suggests that employees' choices are different depending on how close the cost differences are to a reference point, which supports Prospect Theory. Prior research had not used OPC to directly test these two theories in this way.

Though our results support the use of these theories to help us understand benefits choices, future research is needed to address several unavoidable limitations of the present study. First, our situation offered a choice of plans whose non-cost elements were the same. Though not unusual, and quite advantageous for examining how employees respond to cost-related differences, future research should examine the role that OPC plays in conjunction with other health care plan characteristics, such as differences in the health care delivery systems, freedom to choose doctors or treatment centers, coverage for prior existing conditions, etc. No prior studies have estimated OPC in the presence of these other factors, so we have little idea as to how employees may trade off cost savings against other important and valued attributes. OPC may offer a method for determining the dollar equivalent of the utility attached to these other factors.

Second, as with virtually all prior studies, we were not able to measure employees' expectations or predictions of their future medical expenses. We analyzed OPC that occurred after choices were made. While this was important for describing the results of employee decisions and for verifying that choices do seem to be systematically related to eventual cost savings, we cannot tell whether these relationships exist because anticipated costs motivated employee choices or because choices motivated changes in employee behaviors. Future research could collect information on both actual medical expenses and employee predictions of their medical expenses when examining patterns of employee 
choices. Such research could also include measures of employees' knowledge of their benefits or the effort they exert in analyzing their choices.

Third, because our research data reflected prior decisions and realized medical costs, we were not able to measure employee satisfaction with their choices. We do not know if employees whose choices emerged as lower-cost are more satisfied with those choices. Intuition might suggest that employees will be pleased if they lower their costs, but no research has yet examined such questions directly. Once again, a measure of OPC will be essential to determine whether employee reactions to their benefits choices reflect their true awareness of the cost consequences of their decisions, or whether such reactions are based on other facets of the choice.

Finally, our study was a cooperative effort between The Dannon Company and CAHRS, so our findings reflect only a single location at one point in time. This is typical of benefits research, but it means that we cannot be certain that these relationships would exist in other organizations. Replication of our study in other organizations will greatly enhance our ability to draw general theoretical and practical conclusions.

\section{Conclusion: Strategic Benefits Planning through Collaboration}

Generally, our findings suggest that measuring hard-dollar consequences of employee benefits decisions (OPC) can shed light on the patterns and perhaps the processes of those employees' decisions. To fully understand these processes, future researchers and practicing managers need to adopt a strategic perspective on employee benefits that encompasses the antecedents, choices, and consequences of those choices. Our study included some antecedents (age, gender, number of children), measured the choices themselves (Plan A versus Plan B), and examined one particular consequence (out-of-pocket costs). Future research can embellish each of these areas. For example, antecedents might include knowledge of benefit plans, cognitive ability, and motivation to make a good benefits choice. Choice-related variables might include the processes that individuals use to compare their benefit options, their ability to predict future costs, etc. Outcome-related variables might include not only OPC, but also employee attitudes and changes in employee medical behaviors after making certain choices. Our study shows that simply observing the frequency with which a low-premium plan is chosen is not sufficient to make informed theoretical conclusions or judgments about benefits planning. The ability to go beyond such simple statistics is often more a function of limited opportunity than of limited theory or empirical tools. Thus, collaborations such as this one may hold promise for developing a more complete strategic model of employee benefit choices. 
References

Barber, A. E., Dunham, R. B., \& Formisano, R. A. (1992). The impact of flexible benefits on employee satisfaction: A field study. Personnel Psychology, 45, 55-75.

Barringer, M. W., \& Mitchell, O. S. (1994). Workers' preferences among company- provided health insurance plans. Industrial and Labor Relations Review, 48. 141-152.

Davis, K. R., Giles, W. F., \& Feild, H. S. (1988). Opting for benefits: Do job-hunting college seniors envision more money or more benefits? Personnel Administrator, 33(8), 62-68.

Ellis, R. P. (1989). Employee choice of health insurance. The Review of Economics and Statistics, 71, 215223.

Employee Benefit Research Institute (EBRI) (1991). Flexible benefits plans and changing demographics. EBRi Issue Brief, 113.

Employee Benefit Research Institute (EBRI) (1993). Flexible benefits, choice, and work force diversity. EBRI Issue Brief, 139.

Feldman, R., Finch, M., Dowd, B., \& Cassou, S. (1989). The demand for employment- based health insurance plans. Journal of Human Resources. 24, 114- 142.

Feldstein, P. J. (1988). Health care economics. New York: Wiley.

Friedman, M. (1974). Risk aversion and consumer choice of health insurance option. The Review of Economics and Statistics, 56. 209-214.

Friedman, M., \& Savage, L. J. (1948). The utility analysis of choices involving risk, journal of Political Economy. 56, 279-304.

Gerhart, B., \& Milkovich, G. T. (1992). Employee compensation: Research and practice. In M. D.

Dunnette \& L. M. Hough (Eds.), Handbook of industrial and organizational psychology (2nd ed.) (Vol. 3) (pp. 481-569). Palo Alto, CA: Consulting Psychologists Press.

Hewitt Associates. (1994). Salaried employee benefits provided by major U.S. employers in 1993.

Lincolnshire, IL: Hewitt Associates.

Holmer, M. (1984). Tax policy and the demand for health insurance. Journal of Health Economics, 3, 203221.

Kahneman, D., \& Tversky, A. (1979). Prospect theory: An analysis of decision under risk. Econometrica. 47, 263-291.

Lawler, E. D. III, \& Jenkins, G. D. Jr. (1992). Strategic reward systems. In M. D. Dunnette \& L. M. Hough (Eds.), Handbook of industrial and organizational psychology (2nd ed.). Vol. 3 (pp. 961-1055). Palo Alto, CA: Consulting Psychologists Press. 
Mamorsky, J. D. (1990). Employee benefits handbook. New York; Warren, Gorham \& Lamont.

Marquis, M. S., \& Holmer, M. R. (1986). Choice under uncertainty and the demand for health insurance. The Rand Corporation, N-2516-HHS.

McCaffery, R. M. (1992). Employee benefit programs: A total compensation perspective. Boston, MA: PWS-Kent.

McGuire, T. G. (1981). Price and membership in a prepaid group medical practice. Medical Care, 19, 172183.

Mitchell, O. S. (1988). The relation of age to workplace injury. Monthly Labor Review. 111. 8-13.

Piontkowski, D., \& Butler, L. H. (1980). Selection of health insurance by an employee group in northern California. American journal of Public Health, 70, 274-276.

Rosenbloom, J. S., \& Hallman, G. V. (1981). Employee benefit planning. Englewood Cliffs, NJ: PrenticeHall.

Short, P. R, \& Taylor, A. K. (1989). Premiums, benefits, and employee choices of health insurance options, Journal of Health Economics. 8. 293-311.

U.S. Department of Labor. Bureau of Labor Statistics (1990). Employee Benefits in Medium and Large Firms. 1989. Washington, DC: U.S. Government Printing Office.

van Vliet, R. C. A. (1992). Predictability of individual health care expenditures. Journal of Risk and Insurance, 59. 3, 443-460.

Welch, W. P. (1986). The elasticity of demand for health maintenance organization. The Journal of Human Resources, 21. 252-256.

\footnotetext{
${ }^{1}$ A fee-for-service plan means a health plan in which the employee or the insurance pays for every health service provided, at the time it is provided. Other notable works include Ellis (1984), Holmer (1984), Marquis and Holmer (1986), McGuire (1981), and Welch (1986).

${ }^{2}$ Other notable works include Ellis (1984), Holmer (1984), Marquis and Holmer (1986), McGuire (1981), and Welch (1986).

${ }^{3}$ Feldman et al. (1989), McGuire (1981), Piontkowski \& Butler (1980), and Welch (1986).

${ }^{4}$ The Barringer and Mitchell (1994), Feldman et al. (1989), Holmer (1984), Short and Taylor (1989), and Welch (1986) studies examined different plan characteristics and demographic variables. The Ellis (1989), Friedman (1974) and Marquis and Holmer (1986) studies used various statistical techniques to estimate subjects' medical expenses.
} 